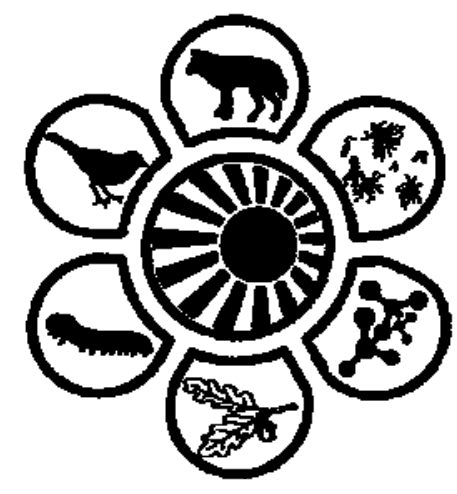

Вісник Дніпропетровського університету. Біологія, екологія.

Vìsnik Dnìpropetrovs'kogo unìversitetu. Seriâ Bìologiâ, ekologiâ

Visnyk of Dnipropetrovsk University. Biology, ecology.

Vìsn. Dnìpropetr. Unìv. Ser. Bìol. Ekol. 2014. 22(2), 156-160.

doi: $10.15421 / 011422$

ISSN 2310-0842 print

ISSN 2312-301X online

www.ecology.dp.ua

УДК 567.5(477.63)

\title{
Остатки рыб из раскопок кургана эпохи бронзы около с. Марьянское (Днепропетровская область, Украина)
}

\author{
А.Н. Ковальчук \\ Национальный научно-природоведческий музей НАН Украины, Киев, Украина
}

\begin{abstract}
Представлены результаты определения остатков рыб, обнаруженных в сосуде при раскопках одного из позднеямных погребений в кургане эпохи бронзы, расположенном в окрестностях с. Марьянское Апостоловского района Днепропетровской области. Установлено наличие 11 видов, относящихся к 9 родам 5 семейств 5 отрядов (Acipenseriformes, Cypriniformes, Siluriformes, Esociformes, Perciformes). Установлено, что карповые рыбы преобладают по количеству видов. Большинство костных остатков в сборах принадлежит судаку, сому и щуке, в то время как плотва, вырезуб и лещ идентифицированы по немногочисленным костям. Это может свидетельствовать о различной роли этих видов в рационе местного населения. Соотношение элементов скелета в сборах свидетельствует о разделке рыбы непосредственно на месте. Для 64 особей рыб по целым костям реконструированы длина тела и масса. Установлено, что все они были половозрелыми и, за исключением сома, щуки и судака, имели небольшие размеры. Учитывая особенности погребальной обрядности населения ямной культуры, кости рыб из курганного погребения около с. Марьянское можно рассматривать в качестве остатков напутственной еды.
\end{abstract}

Ключевые слова: ихтиофауна; эпоха бронзы; Марьянское; напутственная еда

\section{Fish remnants from the excavations of the Bronze Age barrow near Maryanskoe village (Dnepropetrovsk region, Ukraine)}

\author{
O.M. Kovalchuk \\ National Museum of Natural History NAS of Ukraine, Kyiv, Ukraine
}

The Bronze Age mound (2.5-2.3 kya BC) is located near the Maryanskoe village (Apostolovskyi district, Dnepropetrovsk region) and was excavated in 1953. The results of determination of the fish remnants, which were found during the excavation, are presented in the paper. Eleven species belonging to 9 genera, 5 families and 5 orders (Acipenseriformes, Cypriniformes, Siluriformes, Esociformes, Perciformes) were identified: russian sturgeon Acipenser gueldenstaedtii Brandt et Ratzeburg, 1833, stellate sturgeon A. stellatus Pallas, 1771, common ide Idus idus (Linnaeus, 1758), common roach Rutilus rutilus (Linnaeus, 1758), pontic roach R. frisii (Nordmann, 1840), common bream Abramis brama (Linnaeus, 1758), common carp Cyprinus carpio Linnaeus, 1758, tench Tinca tinca (Linnaeus, 1758), european catfish Silurus glanis Linnaeus, 1758, northern pike Esox lucius (Linnaeus, 1758), and zander Sander lucioperca (Linnaeus, 1758). Most of them are quite common in the Dnieper river basin. It was found that carp fishes predominate in the number of species. Most of the bone remnants in the collection belong to zander, catfish and pike, while common roach, pontic roach and common bream are identified by the few bones. This may indicate a different role of these species in the diet of the local population. The ratio of skeletal elements in the collection is the evidence of the fish cutting on the site. Body length and weight was reconstructed for 64 fish specimens. It was found that they were mature and small-sized, except for catfish, pike and perch. Taking into account the characteristics of the funeral rituals of the Yamna culture population, fish bones from the mound near Maryanskoe can be remnants of the parting meal.

Keywords: ichthyofauna; Bronze Age; Maryanskoe; parting meal

Национальный научно-природоведческий музей Национальной академии наук Украины, ул. Богдана Хмельницкого, 15, Киев, 01601, Украина

National Museum of Natural History of the National Academy of Sciences of Ukraine, Bohdan Khmelnitsky Str., 15, Kyiv, 10601, Ukraine Tel.: +38-050-16-61-795.E-mail: Biologiest@ukr.net 


\section{Введение}

Остатки рыб, находимые при археологических раскопках, являются важным источником информации о хозяйственной деятельности людей, а также позволяют установить закономерности изменений, произошедших в составе ихтиофауны того или иного водоема (Svetovidov, 1948; Lebedev, 1960; Makowiecki, 2003). В отдельных случаях находки рыбьих костей проливают свет на слабоизученные аспекты духовной жизни человека прошлых эпох. В этом отношении особый интерес приобретает изучение остатков рыб из погребений, датируемых эпохой бронзы (IV-II тыс. до н. э.).

В ходе работы Марьянского отряда НикопольскоГавриловской экспедиции Института археологии АН УССР под руководством А.И. Фирманской в 1953 г. произведены раскопки кургана № 1, расположенного на берегу высохшей р. Терновка в окрестностях с. Марьянское Апостоловского района Днепропетровской области (Firmanskaja et al., 1953). Всего обнаружены 28 разновозрастных погребений, часть из которых находилась в материке и датирована позднеямным временем (2,52,3 тыс. л. до н. э.). Двойное погребение 23, расположенное в юго-восточном секторе кургана, содержало погребальный инвентарь в виде трех длинных сосудов. Один из них был заполнен костями рыб и млекопитающих (Firmanskaja et al., 1953), которые до настоящего времени не были обработаны.

Целью данной работы является установление видового состава и реконструкция длины тела и массы рыб, остатки которых были обнаружены в заполнении ямы при раскопках позднеямного погребения в кургане эпохи бронзы (III-ІІ тыс. до н. э.) около с. Марьянское Днепропетровской области.

\section{Материал и методы исследований}

Общее количество обработанных остатков составляет 118 экземпляров. 108 костей $(91,5 \%)$ определены до вида, остальные 10 (8,5\%) представлены разрозненными элементами скелета без диагностирующих признаков (обломками ребер и позвонками). Определение систематической принадлежности автор проводил по общепринятой методике с использованием сравнительной ихтиологической коллекции отдела палеозоологии позвоночных Национального научно-природоведческого музея НАН Украины. В статье принята ихтиологическая систематика, приведенная в работе Ю.В. Мовчана (Movchan, 2011). Наименование элементов скелета согласованы с номенклатурой И. Лепиксаара (Lepiksaar, 1994) и В. Раду (Radu, 2005). Измерения сделаны штангенциркулем с точностью 0,1 мм. Для установления размеров рыб составляли пропорцию, куда подставляли данные о размере идентичных костей исследуемой и современной рыб, для которой известны длина тела и мacca (Lebedev, 1960). При подсчетах одна кость рыбы считалась эквивалентной одной особи, поскольку, как было доказано ранее (Lebedev, 1960; Yanish and Antipina, 2013), возможность сохранения двух и более костей от одной рыбы в культурном слое крайне мала. Сведения об индивидуальном возрасте, а также о современной представленности отдельных видов в водоемах Украины и их эктопических предпочтениях почерпнуты из специальной литературы (Makowiecki, 2003; Movchan, 2011).

\section{Результаты и их обсуждение}

В материалах из раскопок погребения присутствуют 11 видов, относящихся к 9 родам 5 семейств (табл. 1): русский осетр - Acipenser gueldenstaedtii Brandt et Ratzeburg, 1833, севрюга - A. stellatus Pallas, 1771, язьIdus idus (Linnaeus, 1758), обыкновенная плотва - Rutilus rutilus (Linnaeus, 1758), вырезуб - Rutilus frisii (Nordmann, 1840), лещ - Abramis brama (Linnaeus, 1758), сазан - Cyprinus carpio Linnaeus, 1758, линь - Tinca tinca (Linnaeus, 1758), европейский сом - Silurus glanis Linnaeus, 1758, обыкновенная щука - Esox lucius (Linnaeus, 1758), обыкновенный судак - Sander lucioperca (Linnaeus, 1758).

Карповые рыбы преобладают по количеству идентифицированных видов ( $\mathrm{n}=6$, или $54,5 \%)$, в то время как другие семейства представлены единичными таксонами видового ранга (табл. 1). Наибольшее количество остатков в сборах принадлежит судаку $(\mathrm{n}=29$, или 26,8\%), сому $(\mathrm{n}=22$, или $20,3 \%)$ и севрюге $(\mathrm{n}=16$, или $14,8 \%)$. Очевидно, эти виды играли значительную роль в питании местного населения. Плотва, вырезуб и лещ представлены немногочисленными костями (табл. 1). Такое распределение мы, вслед за Е.Ю. Яниш и Е.Е. Антипиной (Yanish and Antipina, 2013), объясняем естественной малочисленностью этих видов в водоемах исследуемого региона в указанное время.

В сборах присутствуют разрозненные кости различных отделов краниального (CRA) и посткраниального скелета (PCRA), при небольшом численном преобладании элементов посткраниума. Доля последних составляет 52,6\%, отношение PCRA к CRA - 1,1 (табл. 2). Наличие значительного количества костей черепа свидетельствует о том, что пойманную рыбу, вероятнее всего, разделывали непосредственно на месте. Среди остатков осетровых рыб в сборах наиболее часто встречаются фрагменты I луча грудного плавника, отдельные «жучки», реже - cleithrum, supracleithrale и parasphenoideum. Для костистых рыб характерно гораздо большее разнообразие различных костей (табл. 2). Среди них численно преобладают позвонки, cleithrum и элементы оперкулярного аппарата. Различие в относительном количестве конкретных элементов связано с прочностью самих костей, и в меньшей степени зависит от традиционных способов разделки тушек (Yanish and Antipina, 2013). Наибольшим разнообразием различных костей в сборах характеризуются судак, сом и щука (табл. 2). Среди карповых разнообразными костными остатками представлены сазан и язь.

На основании детального изучения остеологического материала из кургана около с. Марьянское для 64 экземпляров реконструированы длина тела и масса (табл. 3). Рыбы, которым принадлежали остатки, отличались небольшими размерами. Длина тела язя $(\mathrm{n}=5)$ колеблется в пределах 32-37 см при массе 0,68-0,80 кг. Плотва представлена мелкоразмерными особями (длина тела 
25-26 см, масса 0,24-0,25 кг). Несколько крупнее были выловленные сазан (длина тела 33 и $55 \mathrm{~cm}$, масса 1,29 и 2,15 кг) и линь (34 и 42 см, 0,21 и 0,26 кг). Остатки сомов, щук и судаков из заполнения погребальной ямы принадлежат довольно крупным особям (табл. 3). Длина тела сома находится в диапазоне 98-240 см при массе 1,60-3,98 кг (возможно, вес отдельных особей был гораздо большим).

Таксономическая структура рыб по материалам раскопок около с. Марьянское Днепропетровской области (n - количество идентифицированных остатков)

\begin{tabular}{|c|c|c|c|c|}
\hline Семейство & Род & Вид & $\begin{array}{c}\text { Количество } \\
\text { идентифицированных } \\
\text { остатков, } \mathrm{n}\end{array}$ & $\%$ \\
\hline \multirow{2}{*}{$\begin{array}{c}\text { Осетровые - Acipenseridae } \\
\text { Bonaparte, } 1831 \\
\end{array}$} & \multirow{2}{*}{ Acipenser Linnaeus, 1758} & Acipenser gueldenstaedtii & 5 & 4,6 \\
\hline & & A. stellatus & 16 & 14,8 \\
\hline \multirow{6}{*}{$\begin{array}{c}\text { Карповые - Cyprinidae } \\
\text { Fleming, } 1822\end{array}$} & Idus Heckel, 1843 & Idus idus & 9 & 8,3 \\
\hline & \multirow{2}{*}{ Rutilus Rafinesque, 1820} & Rutilus rutilus & 2 & 1,9 \\
\hline & & R. frisii & 2 & 1,9 \\
\hline & Abramis Cuvier, 1816 & Abramis brama & 2 & 1,9 \\
\hline & Cyprinus Linnaeus, 1758 & Cyprinus carpio & 7 & 6,5 \\
\hline & Tinca Cuvier, 1816 & Tinca tinca & 7 & 6,5 \\
\hline Сомовые - Siluridae Cuvier, 1816 & Silurus Linnaeus, 1758 & Silurus glanis & 22 & 20,3 \\
\hline Щуковые - Esocidae Cuvier, 1816 & Esox Linnaeus, 1758 & Esox lucius & 7 & 6,5 \\
\hline Окуневые - Percidae Cuvier, 1816 & Sander Oken, 1817 & Sander lucioperca & 29 & 26,8 \\
\hline
\end{tabular}

Распределение обработанного остеологического материала по элементам скелета

Таблииа 2

\begin{tabular}{|c|c|c|c|c|c|c|c|c|c|c|c|c|c|c|}
\hline \multirow[b]{2}{*}{ Элемент скелета } & \multirow{2}{*}{ 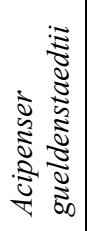 } & \multirow[b]{2}{*}{ 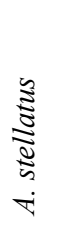 } & \multirow[b]{2}{*}{ 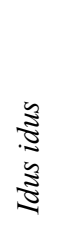 } & \multirow[b]{2}{*}{ 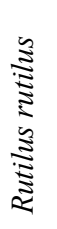 } & \multirow[b]{2}{*}{ 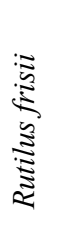 } & \multirow{2}{*}{ 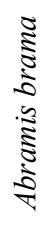 } & \multirow[b]{2}{*}{ 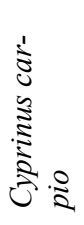 } & \multirow[b]{2}{*}{ 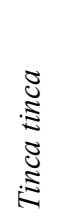 } & \multirow[b]{2}{*}{ 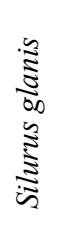 } & \multirow[b]{2}{*}{ 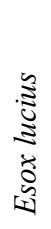 } & \multirow[b]{2}{*}{ 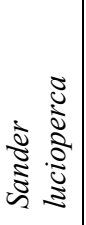 } & \multirow[b]{2}{*}{ 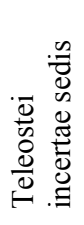 } & \multicolumn{2}{|c|}{$\Sigma$} \\
\hline & & & & & & & & & & & & & $\mathrm{n}$ & $\%$ \\
\hline \multicolumn{15}{|c|}{ Кости краниального скелета (CRA) } \\
\hline Praevomer & - & - & - & - & - & - & - & - & - & 1 & - & - & 1 & 0,8 \\
\hline Parasphenoideum & - & 1 & - & - & - & - & - & - & 1 & 1 & 2 & - & 5 & 4,2 \\
\hline Basioccipitale & - & - & - & - & 1 & - & - & - & - & - & - & - & 1 & 0,8 \\
\hline Praemaxillare & - & - & - & - & - & - & - & - & 1 & - & 2 & - & 3 & 2,6 \\
\hline Maxillare & - & - & - & - & - & - & - & - & 1 & - & 3 & - & 4 & 3,4 \\
\hline Quadratum & - & - & - & - & - & - & - & - & - & - & 1 & - & 1 & 0,8 \\
\hline Articulare & - & - & - & - & - & - & - & - & - & - & 5 & - & 5 & 4,2 \\
\hline Dentale & - & - & - & - & - & - & - & - & - & 3 & 4 & - & 7 & 6,0 \\
\hline Hyomandibulare & - & - & 3 & - & - & - & - & - & - & 1 & 1 & - & 5 & 4,2 \\
\hline Epihyale & - & - & - & - & - & - & - & - & 1 & - & - & - & 1 & 0,8 \\
\hline Praeoperculare & - & - & 1 & 1 & - & 1 & 2 & - & - & - & 2 & - & 7 & 6,0 \\
\hline Operculare & - & - & 5 & - & - & - & 3 & 2 & 1 & - & 1 & - & 12 & 10,2 \\
\hline Interoperculare & - & - & - & - & - & - & - & - & - & - & 1 & - & 1 & 0,8 \\
\hline Suboperculare & - & - & - & - & - & 1 & 1 & - & - & - & 1 & - & 3 & 2,6 \\
\hline \multicolumn{15}{|c|}{ Кости посткраниального скелета (PCRA) } \\
\hline Ceratobranchiale & - & - & - & 1 & 1 & - & 1 & 3 & - & - & - & - & 6 & 5,1 \\
\hline Dentes pharyngiales & - & - & - & - & - & - & - & 2 & - & - & - & - & 2 & 1,7 \\
\hline Ребра & - & - & - & - & - & - & - & - & - & - & - & 2 & 2 & 1,7 \\
\hline Позвонки & - & - & - & - & - & - & - & - & 13 & - & 6 & 4 & 23 & 19,5 \\
\hline Cleithrum & - & 10 & - & - & - & - & - & - & 2 & 1 & - & - & 13 & 11,1 \\
\hline Supracleithrale & - & 1 & - & - & - & - & - & - & - & - & - & & 1 & 0,8 \\
\hline Pinna pectoralis I & 3 & - & - & - & - & - & - & - & 2 & - & - & & 5 & 4,2 \\
\hline Pinnae & - & - & - & - & - & - & - & - & - & - & - & 4 & 4 & 3,4 \\
\hline Marginalia & 2 & 4 & - & - & - & - & - & - & - & - & - & - & 6 & 5,1 \\
\hline
\end{tabular}

Реконструированная длина тела 6 экземпляров щук составляет 36-72 см, масса - 0,87-1,76 кг. Для судаков эти показатели составляют, соответственно, 33-77 см и 1,04-2,40 кг (табл. 3). Учитывая размеры тела и массу отдельных особей, они являлись половозрелыми и были способны к нересту.
Все виды рыб, остатки которых были обнаружены при раскопках, встречаются в составе современной пресноводной ихтиофауны Украины (Movchan, 2011). Большинство из них, за исключением осетровых и вырезуба, являются довольно обычными для бассейна Днепра. 
Важными в контексте сравнения являются сведения о находках рыбьих костей и предметов рыболовного промысла в близких по возрасту археологических памятниках Украины и сопредельных территорий. При раскопках поселения ямной культуры Михайловка II у с. Михайловка Ново-Воронцовского района Херсонской области собраны 236 костей от 120 особей рыб не- установленного таксономического состава (Bibikova, 1963). В материалах раскопок поселения VIII в. до н. э. около с. Балабанешты (Республика Молдова) идентифицированы остатки сазана (Voronenkova, 1964). Л.Д. Житенева (Zhiteneva, 1964) сообщает о находках костей вырезуба, леща, сазана, сома и щуки при раскопках трипольского поселения (III тыс. до н. э.) в долине Днестра.

Реконструированные значения длины тела и массы рыб

Таблица 3

из раскопок около с. Марьянское Днепропетровской области, полученные путем экстраполяции данных

\begin{tabular}{|c|c|c|c|c|c|c|}
\hline \multirow{2}{*}{ Вид } & \multirow{2}{*}{ Элемент скелета } & \multirow{2}{*}{$\mathrm{n}$} & \multicolumn{2}{|c|}{ Длина тела, см } & \multicolumn{2}{|c|}{ Масса тела, кг } \\
\hline & & & $\mathrm{R}$ (min-max) & $\mathrm{M}$ & $\mathrm{R}(\min -\max )$ & $\mathrm{M}$ \\
\hline \multirow{3}{*}{ Idus idus } & praeoperculare & 1 & - & 31 & - & 0,68 \\
\hline & operculare & 1 & - & 37 & - & 0,80 \\
\hline & hyomandibulare & 3 & $32-35$ & 33 & $0,70-0,77$ & 0,72 \\
\hline \multirow{2}{*}{ Rutilus rutilus } & praeoperculare & 1 & - & 26 & - & 0,25 \\
\hline & ceratobranchiale & 1 & - & 25 & - & 0,24 \\
\hline Cyprinus carpio & praeoperculare & 2 & $33 ; 55$ & - & 1,$29 ; 2,15$ & - \\
\hline Tinca tinca & ceratobranchiale & 2 & $34 ; 42$ & - & 0,$21 ; 0,26$ & - \\
\hline \multirow{3}{*}{ Silurus glanis } & pinna pectoralis I & 2 & $98 ; 111$ & - & 1,$60 ; 1,80$ & - \\
\hline & cleithrum & 2 & $176 ; 190$ & - & 3,$06 ; 3,20$ & - \\
\hline & vertebra & 13 & $108-240$ & 130 & $1,78-3,98$ & 2,13 \\
\hline \multirow{4}{*}{ Esox lucius } & parasphenoideum & 1 & - & 43 & - & 1,06 \\
\hline & hyomandibulare & 1 & - & 65 & - & 1,60 \\
\hline & dentale & 3 & $36-72$ & 51 & $0,87-1,76$ & 1,24 \\
\hline & cleithrum & 1 & - & 52 & - & 1,25 \\
\hline \multirow{9}{*}{ Sander lucioperca } & praemaxillare & 2 & $35 ; 40$ & - & 1,$10 ; 1,24$ & - \\
\hline & maxillare & 3 & $67-69$ & 68 & $2,10-2,16$ & 2,13 \\
\hline & quadratum & 1 & - & 45 & - & 1,45 \\
\hline & articulare & 5 & $44-55$ & 51 & $1,37-1,73$ & 1,61 \\
\hline & \begin{tabular}{|l|} 
dentale \\
\end{tabular} & 4 & $58-77$ & 69 & $1,82-2,40$ & 2,10 \\
\hline & hyomandibulare & 1 & - & 52 & - & 1,64 \\
\hline & suboperculare & 1 & - & 48 & - & 1,50 \\
\hline & interoperculare & 1 & - & 56 & - & 1,76 \\
\hline & vertebra & 6 & $33-66$ & 50 & $1,04-2,06$ & 1,55 \\
\hline
\end{tabular}

Глоточные кости карповых рыб обнаружены в заполнении ямы одного из погребений в кургане эпохи бронзы около с. Кондратовка Константиновского района Донецкой области (Kul'baka and Kachur, 1998). Остатки сазана, линя, сома, щуки и судака получены из слоев VIII-V вв. до н. э. поселения Чобручи на обширном мысу левого берега р. Днестр (Kishljaruk, 2011). Население степной Скифии (VII-III вв. до н.э.) оставило после себя рыболовные крючки и многочисленные кости рыб в жертвенных постройках (Ol'hovskij, 1991).

Кочевые племена, жившие на территории Украины в эпоху бронзы, употребляли в пищу уху из речной рыбы, причем погребальная (т. н. напутственная) еда во многом совпадала с обычными повседневными блюдами. Обряд приготовления подношений, которые клались в погребальную яму вместе с телом усопшего, был повсеместно распространен на протяжении III-II тыс. до н. э. (Smirnov, 1996). Обработанные кости рыб из погребения, очевидно, можно рассматривать в качестве остатков напутственной еды.

\section{Выводы}

В материалах раскопок одного из позднеямных погребений (2,5-2,3 тыс. л. до н. э.) в кургане около с. Марьянское Днепропетровской области установлено наличие 11 видов 9 родов рыб, относящихся к 5 семействам. Карповые рыбы преобладают по количеству видов и представлены в сборах 6 видами. Большинство остатков принадлежит судаку, сому и щуке. Соотношение элементов скелета в сборах свидетельствует о разделке рыбы непосредственно на месте. Учитывая особенности погребальной обрядности населения ямной культуры, кости рыб из погребения являются остатками напутственной еды.

\section{Благодарности}

Автор выражает искреннюю благодарность сотрудникам научного архива Института археологии НАН Украины (Киев) за предоставленную возможность работы с отчетом о раскопках, произведенных НикопольскоГавриловской экспедицией в 1953 г.

\section{Библиографические ссылки}

Bibikova, V.I., 1963. Iz istorii izuchenija golocenovoj fauny pozvonochnyh v Vostochnoj Evrope [From the history of the study of Holocene vertebrate fauna in the Eastern Europe]. Prirodnaja Obstanovka i Fauny Proshlogo 1, 119-146 (in Russian). 
Firmanskaja, A.I., Pokrovskaja, E.F., Berezovets, D.T., 1953. Otchet o rabote Mar'janskogo otrjada Nikopol'-Gavrilovskoj ekspedicii za $1953 \mathrm{~g}$. [Report on the work of Maryanskyi unit of the Nikopol-Gavrilovskyi expedition for 1953]. Scientific Archive of the Institute of Archaeology NAS of Ukraine, No. 2078-2079 (in Russian).

Kishljaruk, V.M., 2011. Rybnyj promysel kak strategija zhizneobespechenija drevnih poselenij Nizhnego Pridnestrov'ja [Fishing as livelihood strategies of ancient settlements of Lower Transnistria]. Ecology of Ancient and Traditional Societies. Tjumen', 173-176 (in Russian).

Kul'baka, V., Kachur, V., 1998. Somatychni kul'ty bronzovogo viku pivdnja Shidnoi' Jevropy [Bronze age somatic cults in Southeastern Europe]. Mariupol, VPC PDTU (in Ukrainian).

Lebedev, V.D., 1960. Presnovodnaja chetvertichnaja ihtiofauna Evropejskoj chasti SSSR [Freshwater Quaternary Ichthyofauna of the European part of USSR]. MGU, Moscow (in Russian).

Lepiksaar, J., 1994. Introduction to osteology of fishes for palaeozoologists. Göteborg.

Makowiecki, D., 2003. Historia ryb i rybołówstwa w holocenie na Niżu Polskim w świetle badań archeoichtiologicznych [History of fishes and fishing in Holocene on Polish Lowland in the light of archaeoichthyological studies]. IAiE PAN, Poznań (in Polish).

Movchan, Y.V., 2011. Ryby Ukrainy [Fishes of Ukraine]. Zoloti Vorota, Kyiv (in Ukrainian).
Ol'hovskij, V.S., 1991. Pogrebal'no-pominal'naja obrjadnost' naselenija stepnoj Skifii [Funerary and memorial rites of the steppe Scythia population (VII-III cent. BC)]. Nauka, Moscow (in Russian).

Radu, V., 2005. Atlas for the identification of bony fishes from archaeological sites. Editura Contrast, Bucureşti.

Smirnov, A.M., 1996. Kurgany i katakomby epohi bronzy na Severskom Donce [Mounds and the catacombs of the Bronze Age on the Seversky Donets]. Dissertation for obtaining the scientific degree Cand. Hist. Sci. Moscow (in Russian).

Svetovidov, A.N., 1948. K istorii ihtiofauny r. Dona [On the history of fish fauna of the Don River]. Materialy i issledovanija po arheologii SSSR 8, 124-127 (in Russian).

Voronenkova, L.D., 1964. O rybolovstve drevnih poselenij Podnestrov'ja (III-I tys. 1. do n.je.) [On fishing of ancient settlements on the Dniester river (III-I kya BC)]. Voprosy Ihtiologii 4(3), 599-602 (in Russian).

Yanish, E.Y., Antipina, E.E., 2013. Promyslovye ryby drevnej Ol'vii (I-III vv. n.e.) i ee okrestnostej [Commercial fish from Ancient Olbia (1-3rd centuries AD) and its neighborhood]. Zoologicheskij Zh. 92(9), 1190-1200 (in Russian).

Zhiteneva, L.D., 1964. Promyslovaja fauna ryb i rybolovstvo bassejna Chernogo morja po arheologicheskim materialam [Fishing and fish fauna of the Black Sea fisheries on archaeological materials]. Dissertation for obtaining the scientific degree Cand. Biol. Sci., Moscow (in Russian).

Надійшла до редколегії 11.10.2014 